\title{
A LOGISTICA APLICADA COMO INSTRUMENTO DE RESPONSABILIDADE SOCIOAMBIENTAL: UM ESTUDO DE CASO
}

Jean Carlos Silva Santos, Loana de Oliveira Queiroz

Universidade do Oeste Paulista - UNOESTE, Curso de Engenharia de Produção, Presidente Prudente, SP. Email: eng.loana@hotmail.com

\section{RESUMO}

A procura por soluções ambientais e socioeconômicas no mundo atual tem feito com que as empresas busquem soluções para se adaptarem a política impostas pelos novos consumidores que tem imposto ações de conscientização social e melhorias ambientais em todos os seus setores de produção e também pós-consumo. Assim a logística entra como ferramenta para apoiar na criação de políticas de responsabilidades socioambientais. Este artigo tem como objetivo demonstrar de que forma a logística pode ser trabalhada dentro das organizações com intuito de cooperar com as estratégias de responsabilidade socioambiental. A metodologia constou de pesquisa bibliográfica juntamente com abordagem qualitativa de um estudo de caso. Resultou numa observação onde a logística apoia de forma clara na gestão de políticas de responsabilidade socioambiental. Concluise que a logística é uma ferramenta flexível que pode ser utilizada no intuito de melhorar o âmbito social e também o ambiente em que a empresa se situa.

Palavras-Chave: Logística. Responsabilidade socioambiental. Gestão.Sustentabilidade.

\section{THE LOGISTICS APPLIED AS AN INSTRUMENT OF SOCIAL AND ENVIRONMENTAL RESPONSIBILITY: A CASE STUDY}

\begin{abstract}
The demand for environmental and socioeconomic solutions in today's world has made companies seek solutions to adapt the policy imposed by new consumers who have imposed social awareness actions and environmental improvements in all sectors of production and post-consumer also. So the logistics enters as a tool to support the creation of policies for social and environmental responsibilities. This article aims to demonstrate how the logistics can be worked out within the organizations to cooperate with the social-environmental responsibility strategies. The methodology consisted of bibliographical research together with a qualitative approach a case study. Resulted in a note where the logistics supports clearly on political management of social and environmental responsibility. It is concluded that logistics is a flexible tool that can be used in order to improve the social context and the environment in which the undertaking is situated.
\end{abstract}

Keywords: Logistics. Social and environmental responsibility. Administration. Sustainability. 


\section{INTRODUÇÃO}

A procura por soluções ambientais e socioeconômicas no mundo atual tem feito com que as empresas busquem soluções para se adaptarem a política impostas pelos novos consumidores que por dependência destas grandes empresas em quase todos os aspectos da sua vida, tem imposto ações de conscientização social e melhorias ambientais em todos os seus setores de produção e também pós-consumo.

Este modelo proposto faz com que as empresas procurem se adaptar e investir em produtos de teor ambiental correto, um relacionamento ético com no tratar com o cliente e uma demonstração de valor em questões ligadas aos seus colaboradores, proporcionando não somente virtudes no âmbito social, mas também ambiental.

Consequentemente o assunto responsabilidade socioambiental tem tomado espaço importante no momento das decisões estratégicas das organizações. Esta temática é capaz de exercer um papel muito importante no mundo econômico e na sociedade, capaz de transformar algumas situações referentes ao padrão de vida social, desde que o mercado concilie seus processos produtivos com o estudo socioambiental.

Assim, a empresa pode utilizar ferramentas que cooperem para que esta estratégia funcione, para tanto pode ser utilizado à logística como instrumento diferencial, por conta da sua capacidade de flexibilidade dentro do processo gerencial.

Este artigo tem como objetivo demonstrar de que forma a logística pode ser trabalhada dentro das organizações com intuito de cooperar com as estratégias de responsabilidade socioambiental, não apenas como ferramenta de redução de custos, mas sim de apoio a gerenciamento das cadeias produtivas ou canais de distribuição em prol da sociedade ou do ambiente em que a empresa se situa.

\section{METODOLOGIA}

Por se tratar de uma pesquisa com base em um estudo de caso, utilizou-se de dados de forma quantitativa e qualitativa que de acordo com Chizzotti (1998) e Teixeira (2003) define-se como qualiquantitativa onde sua ferramenta de coleta será através de referências bibliográficas, e com pesquisa exploratória, juntamente com questionários e dados avaliativos, onde são realizadas consultas documentais e pesquisas de campo.

O modelo de pesquisa exploratória leva a uma maior abrangência sobre o tema que viera a ser pesquisado através de levantamento bibliográfico.

"A pesquisa exploratória realiza discussões precisas da situação, quer descobrir os relações existentes entre seus elementos". (CERVO, BERVIAN E DA SILVA, 2006, p.62).

Com base na pesquisa bibliográfica o estudo se torna mais claro, analisando e discutindo fontes publicadas, tais como pesquisa documental, assim se tornando mais fiel e real, não baseando se somente nas analises do autor.

"A pesquisa bibliográfica procura explicar um problema a partir de referencias técnicas publicadas em artigos, livros, dissertações e teses". (CERVO, BERVIAN E DA SILVA, 2006, p.60).

\section{RESULTADOS}

Desde as primeiras organizações o posicionamento sempre foi em busca de uma colocação no mercado econômico que a torne a empresa competitiva frente as demais organizações. Não obstante, os gestores das empresas não conseguem se adequar as variedades de fundamentos que levam a organização ao sucesso constante, pois o mercado varia constantemente.

As organizações fordistas condicionavam seu crescimento a produtos padronizados e processos contínuos de produção de bens (MARTINS E LAUGENI, 1998), onde muitas das vezes nem mesmo o mercado era consultado, ficando nas mãos dos projetistas esta responsabilidade. 
Logo após a segunda guerra mundial, as empresas focaram-se em colocar em primeira ordem a produção com redução de custos, onde as empresas tinham seu diferencial competitivo de acordo com a sua capacidade de produção com uma menor utilização investimentos, porém juntamente com essa etapa de redução de custos o mercado começou a exigir um melhor retorno em seus produtos, ou seja, o mercado começou a desejar qualidade em tudo que era produzido. Assim esta foi à primeira vez em que a empresa começou a sentir que o aspecto externo a ela estava sendo influente no que era produzido e direcionado ao mercado, alterando também a base dos padrões de atuação da empresa (FERREIRA, REIS E PERREIRA, 1997).

Atualmente vemos que num contexto global, há uma desorganização econômica, impregnada através da globalização, portanto para que as empresas se situem em crescimento é essencial que ocorra uma interação entre essas organizações e que estas cooperem entre elas, ou seja, as empresas necessitam ser flexíveis para se adaptarem as barreiras impostas por todo o ambiente externo e não se posicionar de forma nula a ele.

Desta forma, as empresas que desejam se posicionar com um poder de competição maior dentro do mercado, devem ter um poder de relacionamento com os agentes externo maior que as demais (WOOD E ZUFFO, 1997). Assim, as organizações que se destacam não são somente aquelas que têm uma maior quantidade de estoque e uma tecnologia mais avançada na sua gestão, às empresas precisam primeiramente se alocar de forma que consigam se destacar dentro das suas particularidades no relacionamento com os seus clientes e coordenação das suas estratégias existentes adaptando elas a sociedade, de forma que a empresa seja vista através de seus consumidores finais como uma empresa que se importa além do lucro, ou seja, uma empresa que cumpre também com a sua responsabilidade socioambiental.

Para que a empresa possua uma forma de tornar o cliente final parte dela, é necessário que utilize de ferramentas que a interligue com o consumidor.

Neste ponto vemos que a logística se torna parte fundamental para que a empresa consiga esse contato direto ao cliente, pois esta é o elo entre estes dois pontos. De acordo com BALLOU (1993) o objetivo da logística consiste em melhorar de forma completa o nível de serviço que deve ser oferecido ao cliente. Compreende-se então que a logística se torna um fator importante dentro do ponto estratégico da empresa, onde aplicada se relaciona entre os pontos de cliente final e fornecedor, empresa e cliente, onde sua inserção no cenário social é crucial para que o andamento da empresa seja completo.

\section{RESPONSABILIDADE SOCIOAMBIENTAL}

A origem da responsabilidade social esta ligada diretamente as bases que as empresas tiveram em sua origem derivada dos princípios religiosos do século $\mathrm{XX}$ onde alguns estudiosos acreditavam que estas bases religiosas poderiam ser utilizadas para as atividades empresariais, dentre estes o principio da caridade e o principio do gerenciamento (LANTOS, 2001).

Entretanto, o ponto central onde marca a origem da responsabilidade social esta em um livro de um economista americano chamado Howard Bowen, o livro Responsabilidades sociais do homem de negócios, de 1953 onde Bower destaca quais devem ser as responsabilidades que qualquer homem de negocio deve ter frente a sua sociedade (CARROLL, 1999).

$\mathrm{Na}$ década de 60 a 70, as empresas começaram a crescer ainda mais nos Estados unidos e juntamente o conceito de responsabilidade, dentro das décadas de 1950 até o final da década de 1980, Carroll foi o responsável por transmitir este conceito, onde os seus conceitos derivavam da teoria dos stakeholders. (COLTRO, 2004, p.27).

Conforme o crescimento do conceito se evadia pelo globo, foi-se acrescentando ainda mais objetivos as empresas por intermédio desta, tornando de forma essencial a sua utilização e adequação as empresas, de forma que a sua complexidade levou a denominação maior de responsabilidade socioambiental.

\section{DISCUSSÃO}

Colloquium Socialis, Presidente Prudente, v. 01, n. Especial, p.22-26 jan/abr 2017. DOI: 10.5747/cs.2017.v01.nesp.s0004 
Com o intuito de colocar em confronto a hipótese do estudo, selecionamos uma das empresas da região que tem um crescimento considerável atualmente para verificar se a utilização da logística tem determinada influencia na forma em quem é trabalhada a responsabilidade social da empresa. Foi elaborado um questionário e o mesmo foi respondido pelo gestor da empresa atualmente. A empresa selecionada foi o Supermercado Koike de Pirapozinho/SP.

\section{QUESTIONARIO: RESPONSABILIDADE SOCIOAMBIENTAL \\ 1- Como é trabalhada a logística dentro do sistema administrativo na empresa ? \\ Nossa logística de compras é $80 \%$ terceirizada, ou seja, os fornecedores entregam direto na loja, conforme pedidos, alguns diários (carnes, folhagens e hortifrúti), outros semanais (laticínios e frios), outros quinzenais (leite, mercearia, higiene e limpeza) e alguns mensais (mercearia pesada, entre outras). \\ Ha um planejamento de entrega conforme o giro, estoque e vendas e estoque se segurança para que não haja rupturas. Quanto à logística de entrega, trabalhamos com frota própria, com controle de todas as saídas, anotando toda a estrutura de entrega, desde quilometragem até o valor de entrega, onde podemos retirar o custo de cada saída logística.}

\section{2- Existe algum funcionário especifico de controle somente para logística ?}

Temos a fiscal de caixa que faz o controle das entregas e um encarregado dos motoristas faz a escala. Existe um check list diário para controle de todas as informações.

\section{3- A empresa considera necessária a aplicação de ações de responsabilidade socioambiental? Tem aplicado?}

Sim, inclusiva a empresa tem o titulo de empresa cidadã emitido pelo Rotay Club Internacional e o diretor da empresa tem o titulo Paul Heris, conferido aos empresários focados em ações sociais e socioambientais.

\section{4- 0 que a logística tem cooperado para o aumento ou concretização da política de responsabilidade socioambiental da empresa?}

Tem sido positivo considerando a preocupação com a manutenção constante da frota para que não emita gases poluentes em excesso, bem como, além das preocupações com a sustentabilidade, entregando em caixas, diminuindo consideravelmente o número de sacolas plásticas.

\section{5- Que avanços tem sido notados dentro das praticas administrativas por intermédio da logística?}

Os avanços podem ser observados com o a diminuição dos custos de entrega, menor tempo em cada entrega e melhoria da satisfação dos clientes, considerando que as entregas estão mais direcionadas dentro de horários compatíveis com a aceitação dos clientes. Conseguimos operar com dois caminhões na entrega, sendo que somente em dias de alto colume colocarmos o terceiro caminhão.

Antes dos processos atuais tínhamos cerca de 20 dias com três caminhões, sendo que atualmente são apenas 8 dias por mês.

\section{CONCLUSÃO}


Em muitas empresas a logística tem sido a principal ferramenta em busca da gestão completa, por conta da sua capacidade de diversificar os custos e sua flexibilidade de gestão. Cooperando com esta informação, vemos que sua capacidade de contato direto com o cliente a torna também o elo da empresa em seus fins sociais.

Conclui-se então que a logística se aplicada corretamente, pode ser a principal ferramenta das empresas em busca de um contato melhor com seus clientes e também ser o a forma de as empresas agirem de forma ética dentro da sociedade, ou seja, a empresa agir com a sua responsabilidade socioambiental dentro da sociedade.

Para tanto é necessário o engajamento de todos os setores da empresa, dentro de uma cadeia que cumpra com essas responsabilidades impostas.

\section{REFERÊNCIAS}

BALLOU, R. H. Gerenciamento da cadeia de suprimentos: planejamento, organizações e logística empresarial. São Paulo: BOOKMAN, pp 26, 2001.

CARROLL, A. B. Corporate social responsibility: evolution of a definitional construction. Business \& Society, v.38, n.3, p.268-295, 1999. https://doi.org/10.1177/000765039903800303

CERVO, A. L.; BERVIAN, P. A.; SILVA, R. Metodologia Científica. 6. Ed. São Paulo: Person Education Brasil, 2007.

CHIZZOTTI, A. Pesquisa em ciências humanas e sociais. 3.ed. São Paulo: Cortez, 1998

COLTRO, A. Ética e responsabilidade social corporativa: questões contemporâneas. São Paulo: Conhecimento \& Sabedoria, 2004.

MARTINS, P. G.; LAUGENI F. B. Administração da produção. São Paulo: Saraiva, 1998.

FERREIRA, A. A.; REIS, A. C.; PEREIRA, M. I. Gestão empresarial: de Taylor aos nossos dias evolução e tendências da moderna administração de empresas. São Paulo: Pioneira, 1997.

TEIXEIRA, E. B. A análise de dados na pesquisa científica. In: Revista Desenvolvimento em Questão. Itajaí: Editora da UNIJUÍ, ano 1, n.2, p.177-201, jul./dez., 2003.

WOOD JR, T.; ZUFFO, P. K. Supply chain management: uma abordagem estratégica para a logística. In: Encontro da ANPAD, 25, 2001, Campinas, Anais, Rio de Janeiro: Associação nacional dos programas de pós-graduação em administração, set. 2001. 